\section{Obesity in pregnancy, delivery and postpartum period - guidelines and recommendations}

\section{Gebelik, doğum ve doğum sonu dönemde obezite - rehberler ve öneriler}

\section{Bihter Akın ${ }^{1}$}

\section{Özet}

Obezite prevalansı tüm dünyada ve ülkemizde huzla artış göstermektedir. Toplumda artan obezite prevelansı diyabet, kalp hastallğ1 ve belirli kanserler dahil olmak üzere birçok sağllk probleminin görülme durumunun ve kadınlarda aynı zamanda gebelik, doğum ve doğum sonu dönemde komplikasyon görülme olasilgğının da artmasina neden olmaktadır. Bu nedenle obez gebelere doğum ve doğum sonrası dönemde oluşabilecek komplikasyonları da önlemeye yönelik normal kiloda olan gebelerden daha farklı bir bakım verilmelidir. Birçok ülkede bu bakıma yönelik kanıta dayalı çalışmalardan faydalanılarak oluşturulmuş bakım rehberleri bulunmaktadır. Bu derlemede gebelik, doğum ve doğum sonrası dönemde obezite ile ilgili rehberlerin gözden geçirilmesi amaçlanmıştır.

Anahtar Kelimeler: Obezite, gebelik, rehberler.

Keywords: Obesity, pregnancy, guidelines.

(Extended English summary is at the end of this document)

\footnotetext{
${ }^{1}$ Dr. Öğr. Üyesi, Selçuk Üniversitesi, Sağlık Bilimleri Fakültesi, Ebelik Anabilim Dalı, bihterakin@yahoo.com
} 
Akın, B. (2020). Gebelik, doğum ve doğum sonu dönemde obezite - rehberler ve öneriler. Journal of Human Sciences, 17(1), 1-10. doi:10.14687/jhs.v17i1.5629

\section{Giriş}

Obezite çevresel ve genetik faktörlerin etkileşimi sonucu, vücutta enerji dengesinin bozulmasiyla ortaya çıan bir durumdur ve toplumun \%50'sini ilgilendirmektedir (Aydın, 2011; Tunçbilek, 2005; Taşan, 2005). Obezite prevalansı tüm dünyada ve ülkemizde hızla artış göstermektedir (Branca ve ark., 2007). Dünya Sağlık Örgütü (DSÖ) verilerine göre, 2016 yllında 18 yaş ve üstü yetişkinlerin \%39'unun fazla kilolu \%13'ünün ise obez olduğu belirtilmiştir (Obesity and overweight, WHO, 2018). Obezite sıklığ1 ile ilgili ülkemizde yapılan çalışmalarda elde edilen veriler farklı olsa da genel olarak erişkin Türk toplumunda her üç kadın ve her beş erkekten biri obez sınıfina girmektedir (Ural ve ark., 2018; Türkiye Sağlık Araştırması, 2016). Toplumda artan obezite prevelansı diyabet, kalp hastalı̆̆ ve belirli kanserler dahil olmak üzere birçok sağlık probleminin görülme durumunun (Guh ve ark., 2009) ve kadınlarda aynı zamanda gebelik, doğum ve doğum sonu dönemde komplikasyon görülme olasıllı̆̆ının da artmasına neden olmaktadır (Körükçü ve Kukulu, 2018). Bu nedenle kadınların mümkünse gebe kalmadan önce ideal kiloya ulaşması sağlanmalı, fazla kiloluyken gebe kaldıysa alması gerekenden fazla ya da az kilo almasını önlemeye yönelik önlemler alınmalıdır.

\subsection{Gebelikte Kilo Alımı}

Gebelikte kilo alımına ilişkin öneriler anne ve bebek açısından gebeliğin en iyi şekilde sonuçlanması amacına yöneliktir. Amerikan Tip Enstitüsü (Institute of Medicine - IOM), 1990 yılından beri gebelikte alınması gereken kilo miktarı ile ilgili rehberler yayınlamaktadır. $\mathrm{Bu}$ rehberlerde amaç düşük kilolu, normal ve fazla kilolu olarak gebe kalan kadınların alması gerekenden fazla ya da az kilo almasını engelleyerek gebe, fetüs ve yenidoğan açısından oluşabilecek komplikasyonların önlenmesidir (Weight Gain During Pregnancy: Reexamining the Guidelines IOM, 2009). Bu rehberlerde daha çok gebelik boyunca kilo alımının yenidoğanın vücut ağırlı̆̆1 üzerindeki etkilerine değinilmiştir. Daha sonra IOM ve NRC (National Research Council - Ulusal Araştırma Konseyi) birlikte 2009 yılında DSÖ'nün obezite sinıflandırmasını temel alınmış ve beden kitle indeksi düzeylerine göre gebelikte kilo alımını düzenleyen bir öneri kılavuzu yayınlamıştır (Weight Gain During Pregnancy: Reexamining the Guidelines IOM 2009) (Tablo 1).

\section{Tablo 1. Gebelik öncesi BKİ- Beden Kitle İndeksi* (BMI- Body Mass Index) değerlerine göre gebelik sırasında kilo alımı önerileri}

\begin{tabular}{|l|l|l|l|}
\hline $\begin{array}{l}\text { Gebelik Ağırlık } \\
\text { Kategorisi }\end{array}$ & BKİ (DSÖ) $\mathrm{kg} / \mathrm{m}^{\mathbf{2}}$ & $\begin{array}{l}\text { Önerilen toplam kilo } \\
\text { alımı aralığ1 } \mathbf{( k g )}\end{array}$ & $\begin{array}{l}\text { İkinci ve üçüncü } \\
\text { trimesterde önerilen } \\
\text { kilo alımı aralığ1 } \\
\text { (g/hafta) }\end{array}$ \\
\hline Düşük kilolu & $<18.5$ & $12.7-18.1$ & $450-590$ \\
\hline Normal & $18.5-24.9$ & $11.3-15.9$ & $360-450$ \\
\hline Fazla kilolu & $25.0-29.9$ & $6.8-11.3$ & $220-320$ \\
\hline Obez & $\geq 30.0$ & $5.0-9.1$ & $180-270$ \\
\hline
\end{tabular}

*BKİ (Beden Kitle İndeksi): Kilogram olarak vücut ağırlı̆̆ının metre cinsinden boy uzunluğunun karesine bölünmesiyle hesaplanmaktadır.

Yeni Zelenda Sağlık Bakanlığı 2014 yılında 'Gebelikte Sağlıklı Kilo Alımı İçin Rehber' başlığıyla yayınladıkları rehberde gebelik öncesi, gebelik boyunca ve doğum sonrası dönemde sağlıklı kilo alımı ile ilgili önerilerde bulunmuşlardır (Carr, 2014). Gebelere gebelik boyunca haftalık olarak aldıkları kilo miktarını kaydetmelerini, haftada en az üç kez olmak üzere egzersiz yapmalarını önermisslerdir. Sağlık profesyonellerine de gebeliğin onuncu haftasına kadar gebeleri tespit edip BKİni belirlemeli ve BKİne göre kilo alımı konusunda önerilerde bulunmaları tavsiye edilmiştir. Postpartum dönemde de sağlıklı gıda tüketmenin, fiziksel aktivitede bulunmanın ve emzirmenin doğum öncesi kiloya dönüsste faydalı olduğu belirtilmiştir (Carr, 2014). Tüm rehberlerde fazla kilolu 
Akın, B. (2020). Gebelik, doğum ve doğum sonu dönemde obezite - rehberler ve öneriler. Journal of Human Sciences, 17(1), 1-10. doi:10.14687/jhs.v17i1.5629

ve obez gebelerde kilo alımının daha az olması önerilmektedir (Rasmussen ve ark., 2009; Weight Gain During Pregnancy: Reexamining the Guidelines IOM 2009; Carr, 2014).

\subsection{Obezitenin Gebelik, Doğum ve Doğum Sonrası Dönem Üzerine Etkisi}

Gebelikte alınan kilonun önemi büyüktür ve gebeliğin başlangıcından sonuna kadar anne ve bebeğin sağlı̆̆ ile yakından ilişkilidir (Marchi ve ark. 2016; Gaillard ve ark., 2016). Obez anneler arasında prenatal ve peripartum mortalite görülme oranı obez olmayan annelerden $\% 50$ daha fazladır (Lewis, 2004). Maternal mortaliteye ek olarak, maternal obezitenin diğer komorbid durumlarla da ilişkili olduğu bildirilmiştir. Bu komplikasyonların en sık görülenleri arasında gestasyonel diabetes mellitus (GDM) (Hedderson ve ark., 2008), hipertansif bozukluklar (Sibai ve ark., 1995) ve sezaryen doğum (Aktulay ve ark., 2012; Chu ve ark., 2007) yer almaktadır. Maternal obezite annenin yanı sıra fetüs için nöral tüp defekti, konjenital anomali, prematürite, makrozomi, yoğun bakım ünitesine yatış, ölü doğum ve çocukluk ve adolesan dönemde obezite risklerini artırmaktadır (Huang ve ark., 2017; Dündar ve ark., Kazemian ve ark., 2014; Thrift, 2014; Sharifzadeh ve ark., 2014; Marchi ve ark., 2016; Leonard ve ark., 2017). Ayrica obez gebelerde post operatif venöz tromboemboli ve yara yeri enfeksiyonu gibi doğum ve sezaryen ile ilgili komplikasyonlar daha sık görülmektedir (Davies ve ark., 2010; Rankin ve ark., 2010). Yapılan bir çalışmada sezaryen sırasında spinal anestezi sonrası gelişen rölatif hipotansiyonun BKI $40 \mathrm{~kg} / \mathrm{m}^{2}$ nin üzerinde olan kadınlarda daha belirgin olduğu ve bu durumun yenidoğan kan gazı sonuçlarını da olumsuz etkilediği belirlenmiştir (Powell ve ark., 2017). Avcı ve ark. (2015) da çalışmalarında obez gebelerde obez olmayan gebelere oranla sezaryen ile doğum, prematüre doğum, omuz distosisi, postpartum enfeksiyon oranlarını anlamlı derecede yüksek bulmuştur (Avcı ve ark., 2015). Anestezi açısından da komplikasyon oluşma olasılı̆̆ daha fazladır. Aşırı yağ dokusu varlığı epidural ve spinal anestezi uygulamasını zorlaştırabilmektedir (Biel ve ark., 2017; Väänänen ve ark,. 2017). Obez kadınların mümkünse gebelik öncesi dönemde kilo vermesi, gebeliğin erken dönemlerinden itibaren sıkı kilo alımı kontrolü, gelişebilecek komplikasyonların erken dönemde tanımlanması, intrapartum dönemde ise tecrübeli bir ekip tarafindan takip edilmeleri gerekmektedir (Bulut ve Mihmanl, 2014; Velipaşaoğlu ve Tanır, 2018).

\section{Gebelik ve Doğum Sonrası Dönemde Obezite İle İlgili Rehberler}

Gebelik, doğum ve postpartum döneminde obezite ilgili kanıta dayalı çalışmalardan faydalanılarak oluşturulan değişik ülkelere ait birçok rehber bulunmaktadır. Bu rehberler ve hem gebeler hem de sağlık profesyonellerine sunduğu öneriler şunlardır:

2.1. Gebelikte Obezitenin Yönetimi Rehberi (Royal College of Obstetricians and Gynaecologists (RCOG) - Kraliyet Kadın Doğum Uzmanı ve Jinekologlar Komitesi İngiltere 2010)

Bu rehber İngiltere Kraliyet Kadın Doğum Uzmanı ve Jinekologlar Komitesi tarafından Medline, Cochrane ve EMBASE gibi kanıt temelli veri tabanları araştırılarak elde edilen verilerden faydalanarak oluşturulmuştur.

\subsection{1. Öneriler}

- Gebe kalmak isteyen ve BKI $30 \mathrm{~kg} / \mathrm{m}^{2}$ nin üzerinde olan kadınlar gebelik öncesi dönemde obezite ve gebelik komplikasyonları konusunda bilgilendirilmeli ve mümkünse gebe kalmadan önce fazla kilolarını vermeleri önerilmelidir.

- Ayrıca yine bu kadınlara günde $5 \mathrm{mg}$. folik asit almaları ve gebeliğin birinci trimestri boyunca devam etmeleri önerilir (fetüste nöral tüp defekti riski artacağı için).

- Obez gebelerde gestasyonel diabet ve preeklampsi riski daha da artacağı için kan şekeri ve tansiyon takiplerinde daha hassas davranılmalıdır. 
- Obez gebelerde anesteziye bağlı maternal mortalite oranı yüksek olduğu için BKİ 40 $\mathrm{kg} / \mathrm{m}^{2}$ nin üzerinde olan gebelerin obstetrik anestezistler tarafindan konsulte edilmesi istenmelidir.

- BKİ $40 \mathrm{~kg} / \mathrm{m}^{2}$ ve üzerinde olan gebeler en az altı yıl eğitim görmüş, tecrübeli bir kadın doğum uzmanı ve anestezistin sürekli bulunduğu ve yenidoğan yoğun bakım ünitesine sahip bir kurumda doğum yapmalıdır.

- BKİ $30 \mathrm{~kg} / \mathrm{m}^{2}$ ve üzerinde olan gebelerde sezaryen sonrası enfeksiyon görülme oranları yüksektir. Profilaktif olarak sezaryen öncesi antibiyotik başlananlarda başlanmayanlara oranla postpartum enfeksiyon daha az görülmüsstür.

- BKİ $30 \mathrm{~kg} / \mathrm{m}^{2}$ ve üzerinde olan ve gestasyonel diyabet görülen kadınlarda doğumu takip eden beş yıl içerisinde Tip 2 diyabet görülme oranı yüksektir.

- Obez gebeler doğum sonu dönemde tromboembolizm, postpartum kanama ve enfeksiyon yönünden izlenmelidir (CMACE/RCOG Joint Guideline: Management of Women with Obesity in Pregnancy, 2013).

2.2. Gebelikte Obezite Rehberi (The American College of Obstetricians and Gynecologists (ACOG) - Amerikan Obstetri ve Jinekoloji Derneği - Amerika 2013)

Amerika'da her üç kadından biri obez, her iki kadından biri gebeliğinde kilolu ya da obez kategorisinde yer almaktadır. Obezitenin gebelik ve fetus üzerinde olumsuz etkileri olduğundan gebelerin kilo alımını kontrol etmeleri konusunda cesaretlendirilmeleri gerekmektedir.

\subsection{1. Öneriler}

- Gebelik düşünen kadınlar gebelikte obezitenin riskleri hakkında bilgilendirilmeli ve kilo kontrolü konusunda teşvik edilmeli,

- Antenatal takiplerin hepsinde kilo ve boy kaydedilmeli ve BKİ hesaplanmal,

- Kilolu ve obez kadınların beslenmesi düzenlenmeli ve fiziksel aktivite konusunda cesaretlendirilmeli,

- Daha önce sezaryen olmuş, obezite sınırları içindeki gebeler tromboembolizm yönünden değerlendirilmeli ve profilaktik olarak antikoagulan başlanmalı,

- Sezaryen sonrası enfeksiyon riskine karşı profilaktik olarak antibiyotik başlanmalı,

- Erken dönemde anestezi konsültasyonu istenmelidir (ACOG, 2013).

\subsection{Obezite ve Gebelik Klinik Uygulama Rehberi (İrlanda, 2013)}

Medline, EMBASE ve Cochrane Library'deki on yıllık süreçte yapılmış çalışmalardan elde edilen kanıt temelli bilgiler ile düzenlenmiştir.

\subsection{1. Öneriler}

- Gebelik düşünen obez kadınlar gebe kalmadan önce kilo vermeleri konusunda cesaretlendirilmelidir. Obezitenin PCOS (polikistik over sendromu) ve anovulasyon ile ilişkili olduğu kanıtlanmıştır. Obez gebelerin yenidoğanlarında normal kilodaki gebelere oranla konjenital malformasyon, nöral tüp defekti görülme oranı yüksektir. Bu yüzden obez kadınlar gebe kalmadan önce $5 \mathrm{mg}$. folik asit kullanmaya başlamalı ve gebeliğin birinci trimestrinin sonuna kadar devam etmelidir.

- BKİ $35 \mathrm{~kg} / \mathrm{m}^{2}$ ve üzeri olan gebelerin gelişebilecek komplikasyonlar açısından evde doğum yapmaları uygun değildir. BKI $40 \mathrm{~kg} / \mathrm{m}^{2}$ ve üzeri gebelerde önceden anestezi konsultasyonu istenmeli ve acil şartları taşıyan bir klinikte doğum yapması sağlanmalıdır.

- Gebelere gebelik boyunca sağlıklı beslenmenin önemi anlatılmalıdır. Obez gebelerde ve yenidoğanlarında vitamin $\mathrm{D}$ eksikliği görülme oranı yüksektir. Bu yüzden gebelik ve emzirme boyunca 10 mikrogram (400 IU) D vitamini alınması önerilmektedir. 
- Gebelik boyunca kilo alımı normal kilodaki gebelere oranla daha az olmalıdır.

- Operasyon süresini ve kanamayı arttıracağından dolayı, transvers abdominal insizyondan kaçınılmalıdır. Profilaktik olarak antibiyotik başlanmalıdır.

- Hipertansiyon ve preeklampsi tüm gebeler için riskli bir durumdur. Yapılan çalışmalar BKI'nde $5-7 \mathrm{~kg} / \mathrm{m}^{2}$ artışın preeklampsi riskini iki katına çıardığını göstermiştir (O’Brien ve ark., 2003).

- Obez bireylerde kan basıncı ölçülürken kullanılan tansiyon manşonunun boyutu da önemlidir. İlk antenatal ziyarette tüm gebelerin özellikle BKİ $29.9 \mathrm{~kg} / \mathrm{m}^{2}$ nnin üzerinde olanların orta kol çevresinin (Middle Arm Circumference-MAC) ölçülmesi önerilmektedir. MAC 33 cm'den büyük ise, daha sonra kan basıncı ölçümü için geniş tansiyon manşonu kullanilmalidir.

- Yapilan çalışmalar obez gebelerde ölü doğum riskinin normal kilodaki gebelere oranla 1.47 kat daha fazla olduğunu göstermiştir. Ölü doğumların doğrudan obezite ya da obezitenin neden olduğu hipertansiyon ya da gestasyonel diyabet kaynaklı olduğu düşünülmektedir. Morbid obez kadınlarda, ultrason, kardiotokografi veya fetal izlem teknik olarak daha zordur. Obez kadinların ultrason muayenelerinin daha dikkatli yapilmasi gerekmektedir.

- Obez gebelerde GDM görülme riski normal popülasyondaki gebelerden daha fazladır. BKI $30 \mathrm{~kg} / \mathrm{m}^{2}$ ve üzeri olan gebelere 14 . ve 28. gebelik haftasında mutlaka OGTT uygulanmalıdır. Gebelikte OGTT yüksek çıkan gebeler postpartum dönemde Tip 2 DM yönünden mutlaka değerlendirilmelidir.

- Yapılan çalışmalar obez gebelerde distosi ve kanama riskinin daha yüksek olduğunu göstermiştir. Travay süresince fetal kalp atım hızının external olarak izlemi zor olacağı için internal olarak izlenmesi tavsiye edilmektedir.

- Danimarka'da yapılan bir çalışmada erken dönem gebelikte sigara içmenin ve obezitenin tromboembolizm açısından risk oluşturduğu belirtilmiştir (Larsen ve ark., 2007). Obez gebelerde rutin olarak tromboproflaksi tavsiye edilmemekle birlikte BKİ $40 \mathrm{~kg} / \mathrm{m}^{2}$ ve üzeri olanlarda doğum şekline bakılmaksızın tromboproflaksi önerilmektedir.

- Obez kadınları postpartum dönemde emzirmenin etkinliğinin sağlanması açısından daha fazla desteklenmesi gerekmektedir. Bariatrik cerrahi (obezite cerrahisi) ameliyatı geçirmiş emziren kadınlar vitamin ve mineral takviyesi ile desteklenmelidir.

\subsubsection{Hastane Gereçleri ve Tesisleri}

Doğum ünitelerinde standart tesisler ve ekipmanlar morbid obez bir kadının obstetrik bakımı için yeterli olmayabilir. Her birimin uygun genişlikleri ile obez hasta için kullanılabilirliğini belirlemek için şunlar yapılmalıdır.

- Tekerlekli sandalyeler ve doğum yatakları,

- Çalışma masaları ve arabaları,

- Kolsuz sandalyeler,

- Ultrason taraması için geniş kanepeler,

- Tart1,

- Büyük kan basıncı manşonları,

- Uzun epidural ve spinal iğneler,

- Kaldırma ekipmani,

- Büyük beden önlük,

- Geniş tuvaletler,

- Geniş ve rahat dolaşım alanı, 

17(1), 1-10. doi:10.14687/jhs.v17i1.5629

- Erişilebilir kapı genişlikleri ve eşik bulunmalıdır (Obesity and Pregnancy Clinical Practice Guideline, 2013).

\subsection{Queensland Klinik Rehberleri: Gebelikte Obezite (Avustralya-2015)}

\subsection{1. Öneriler}

- İnfertilite tedavisi görecek olan obez kadınlar tedaviye başlamadan önce kilo vermeleri için desteklenmelidir.

- Özellikle bariatrik cerrahi operasyonu geçiren kadınları kilo kaybı stabil olduktan sonra gebe kalması konusunda uyarılmalıdır.

- Kadınları hipertansiyon ve Tip 2 diyabet açısından değerlendirilmelidir.

- Multidisipliner sağlık hizmetinin bir parçası olarak obstetrisyen ve ebeler gebenin takiplerinde rutin olarak bir diyetisyenle birlikte çalışmalıdır.

- 28-32. haftalarda fetal büyümeyi değerlendirmek için rutin bir ultrason taramas1 önerilmektedir.

- Kadına haftanın çoğu gününde 30 dakikalık fiziksel aktivite (yürüyüş) önerisinde bulunulmalidir.

- İntarapartum dönemde omuz distosisi riskinin artması nedeniyle bu konuda dikkatli olunması önerilmektedir. BKİ $35 \mathrm{~kg} / \mathrm{m}^{2}$ 'den büyük olan kadınların suda doğum yapması önerilmemektedir. Doğum eyleminin özellikle üçüncü evresinde doğum sonrası kanama riski fazla olduğu için obez kadınlar kanama açısından daha sık değerlendirilmeli, uterotonik ilaçlar ve bu ilaçların uygulanması için daha uzun iğne uçları bulundurulmalıdır.

- Sezaryen ile doğum yapan kadınların erken mobilize olmaları konusunda cesaretlendirilmesi önerilmektedir.

- GDM'li kadınlara, OGTT'nin önemi hakkında bilgi verilmeli ve doğum sonrası 6-12. haftalar arasında tekrar tarama yapılması önerilmektedir.

- Emzirmenin erken dönemde başlatılması ve desteklenmesi, taburculuk sonrası da kadının emzirme destek gruplarına yönlendirilmesi bu rehberde bulunan önerilerdendir (Queensland Clinical Guideline: Obesity in Pregnancy, 2015).

\subsection{Yeni Zelenda Gebelikte Obezitenin Yönetimi Rehberi (2017)}

\subsection{1. Öneriler}

- Gebelik öncesi dönemde obezite ve riskleri konusunda gebelik düşünen kadın bilgilendirilmelidir. Egzersiz yapması konusunda teşvik edilmelidir.

- Gebelik öncesi dönemde obezite cerrahisi geçiren kadınlarda intrauterin gelişme geriliği (IUGR) gelişme olasılığ1 yüksek olacağından dolayı diyetisyen ile görüşülerek diyet düzenlemesi yapılmalıdır. Bu gebelere vitamin B12, demir, folat, vitamin D ve kalsiyum takviyesi yapilmalıdır.

- Nöral tüp defekti riskinde artış göz önüne alındığında, BMI> $30 \mathrm{~kg} / \mathrm{m}^{2}$ olan kadınlar için yüksek doz folat $(5 \mathrm{mg}$ ) tavsiye edilir.

- Özellikle obez kadınlarda, gebelikte H1N1 (İnflüenza Virüsu) ile ilişkili maternal morbiditede önemli artışın farkında olunması ve bu kadınların gebelik öncesi dönemde aş1lanması gerekmektedir.

- Klinikler obez gebeler için uygun ortamlar sağlamalıdır. Bunun için geniş tansiyon manşonları, geniş oturma grupları bulunmalıdır.

- Beslenme ve gebelik boyunca kilo alımı konusunda IOM' un önerileri dikkate alınmaktadır. Gestasyonel diyabet taraması, doğumdan önceki dönemde anestezi konsültasyonu istenmesi, fetal değerlendirmenin dikkatlice değerlendirilmesi bu rehberde yer alan önerilerdendir (Management of Obesity in Pregnancy, 2017). 
Akın, B. (2020). Gebelik, doğum ve doğum sonu dönemde obezite - rehberler ve öneriler. Journal of Human Sciences, 17(1), 1-10. doi:10.14687/jhs.v17i1.5629

\section{Sonuç ve Öneriler}

Obezite prevalansı tüm dünyada ve ülkemizde hızla artsş göstermektedir. Toplumda artan obezite prevelansı diyabet, kalp hastalı̆̆ ve belirli kanserler dahil olmak üzere birçok sağlik probleminin görülme durumunun ve kadınlarda aynı zamanda gebelik, doğum ve doğum sonu dönemde komplikasyon görülme olasilı̆ıının da artmasına neden olmaktadır. Bu nedenle obez gebelere, doğum ve doğum sonrası dönemde oluşabilecek komplikasyonları önlemeye yönelik normal kiloda olan gebelerden daha farklı bir bakım verilmelidir. Ülkemizde Sağlık Bakanlı̆̆1 tarafindan yayımlanan Riskli Gebelik Yönetim Rehberi'nde gebelik ve obeziteye değinilmiş; BKİ 40 $\mathrm{kg} / \mathrm{m}^{2}$ nin altında olan tüm lohusalara tromboprofilaksi uygulanması önerilmiştir. Ancak gebelik ve obeziteye özel bir bakım rehberi bulunmamaktadır. Gebelik, doğum ve doğum sonrası dönemde oluşabilecek komplikasyonlara yönelik koruyucu önlemleri zamanında almak; komplikasyon geliştiğinde ise yeterli ekipman ve personel ile zamanında müdahale etmek anne ve bebek sağlığını korumak açısından çok önemlidir. Ülkemizde de anne ve bebek ölümlerini önleme çalışmaları kapsamında; obez gebelerin gebelik, doğum ve doğum sonu dönemde bakım sürecine yönelik güncel literatüre dayalı kanıt temelli bakım rehberlerin geliştirilmesine ihtiyaç duyulmaktadır.

\section{Kaynaklar}

Aktulay, A., Yörük, Ö., Üstün, Y. E., Eyi, E. G. Y., \& Mollamahmutoğlu, L. (2012). Obezitenin Doğum Şekline Etkisi. Jinekoloji-Obstetrik ve Neonatoloji Tip Dergisi, 8 (33).

American College of Obstetricians and Gynecologists, ACOG Committee Opinion No: 548: Weight gain during pregnancy. Obstet Gynecol , 2013;121:210-212

Avc1, M. E., Şanlıkan, F., Celik, M., Avcı, A., Kocaer, M., \& Göçmen, A. (2015). Effects of maternal obesity on antenatal, perinatal and neonatal outcomes. The Journal of Maternal-Fetal \& Neonatal Medicine, 28 (17), 2080-2083.

Aydın, Y. (2012). Fruktoz Bazlı Beslenme, Obesite, İnsulin Direnci Ve Kanser. Düzce Tap Dergisi, 14 (3), 9798.

Biel, F. M., Marshall, N. E., \& Snowden, J. M. (2017). Maternal body mass index and regional anaesthesia use at term: prevalence and complications. Paediatric and perinatal epidemiology, 31(6), 495-505.

Branca, F., Nikogosian, H., Lobstein T. (2007). The Challenge of obesity in the WHO Europan Region and the strategies for http://www.euro.who.int/ data/assets/pdf file/0008/98243/E89858.pdf Erişim tarihi: 15.11.2018

Bulut, B. Mihmanl, V. (2010). Obezite ve Gebelik, Okmeydan Trp Dergisi, 1:24-28, View Article: doi:10.5222/otd.supp1.2014.024

Carr ,H., Pelvin, B., Ozturk, K., Aitken, E., Hadrup, A.,Tuohy ,P., Hussey ,A., Guidance for Healthy Weight Gain in Pregnancy 2014. Erişim adresi: www.health.govt.nz Erişim tarihi: 09.10.2018

Chu, S. Y., Kim, S. Y., Schmid, C. H., Dietz, P. M., Callaghan, W. M., Lau, J., \& Curtis, K. M. (2007). Maternal obesity and risk of cesarean delivery: a meta- analysis. Obesity reviews, 8(5), 385-394.

CMACE/RCOG Joint Guideline : Management of Women with Obesity in Pregnancy (2013) Erişim adresi: https://www.oaa-anaes.ac.uk/assets/ managed/editor/File/Reports/2010 CMACE-

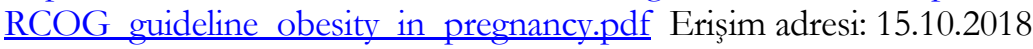

Davies, G. A., Maxwell, C., McLeod, L., Gagnon, R., Basso, M., Bos, H. (2010). Society of Obstetricians and Gynaecologists of Canada. Obesity in pregnancy. J Obstetric Gynaecol Can, 32(2):165-173.

Dündar, Ö., Çiftpınar, T., Tütüncü, L., Ergür, A. R., Atay, M. V., \& Müngen, E. (2008). Gebelik öncesi maternal vücut kitle indeksinin perinatal sonuçlara etkisi. Perinatoloji Dergisi, 16 (2), 43-48.

Gaillard R, Welten M, Oddy WH, Beilin LJ, Mori TA, Jaddoe VW, Huang RC. (2016). Associations of maternal prepregnancy body mass index and gestational weight gain with cardio-metabolic risk factors in adolescent offspring: a prospective cohort study. BCOG, 123(2):207-16. doi: 10.1111/1471-0528.13700. Epub 2015 Nov 3.

Guh, D. P., Zhang, W., Bansback, N., Amarsi, Z., Birmingham, C. L., \& Anis, A. H. (2009). The incidence of co-morbidities related to obesity and overweight: a systematic review and meta-analysis. $B M C$ public health, 9 (1), 88. 
Akın, B. (2020). Gebelik, doğum ve doğum sonu dönemde obezite - rehberler ve öneriler. Journal of Human Sciences, 17(1), 1-10. doi:10.14687/jhs.v17i1.5629

Hedderson, M. M., Williams, M. A., Holt, V. L., Weiss, N. S., \& Ferrara, A. (2008). Body mass index and weight gain prior to pregnancy and risk of gestational diabetes mellitus. American journal of obstetrics and gynecology, 198 (4), 409-e1.

Huang, H. Y., Chen, H. L., \& Feng, L. P. (2017). Maternal obesity and the risk of neural tube defects in offspring: A meta-analysis. Obesity research \& clinical practice, 11(2), 188-197. doi: 10.1016/j.orcp.2016.04.005. Epub 2016 May 5.

Kazemian, E., Sotoudeh, G., Dorosty-Motlagh, A. R., Eshraghian, M. R., Bagheri, M. (2014). Maternal obesity and energy intake as risk factors of pregnancy-induced hypertension among Iranian women. L Health Popul Nutr., 32 (3):486-93.

Körükcü, Ö., \& Kukulu, K. (2011). Obezitenin Üreme Sistemi Üzerine Etkisi. TAF Preventive Medicine Bulletin, 10 (2) :231-238.

Larsen, T. B., Sørensen, H. T., Gislum, M., \& Johnsen, S. P. (2007). Maternal smoking, obesity, and risk of venous thromboembolism during pregnancy and the puerperium: a population-based nested casecontrol study. Thrombosis research, 120 (4), 505-509.

Leonard, S. A., Rasmussen, K. M., King, J. C., \& Abrams, B. (2017). Trajectories of maternal weight from before pregnancy through postpartum and associations with childhood obesity. The American journal of clinical nutrition, 106 (5), 1295-1301.

Lewis G. Why Mothers Die 2000-2002 The Sixth Report of the Confidential Enquiries into Maternal Deaths in the United Kingdom. http://www.hqip.org.uk/assets/NCAPOP-Library/CMACEReports/33.-2004-Why-Mothers-Die-2000-2002-The-Sixth-Report-of-the-Confidential-Enquiriesinto-Maternal-Deaths-in-the-UK.pdf. Published November 2004.

Management of Obesity in Pregnancy, NEW College Statement C-Obs 49 1st Endorsed: March 2013 Current: $\quad$ September $2013 \quad$ Erişim adresi: https://www.ranzcog.edu.au/RANZCOG SITE/media/RANZCOGMEDIA/Women's\%20Health/Statement $\% 20$ and $\% 20$ guidelines/Clinical-Obstetrics/CObs 49 Management-of-Obesity-in-Pregnancy-Review-Sep-2013.pdf?ext=.pdf Erişim tarihi: 15.11.2018

Marchi, J., Berg, M., Dencker, A., Olander, E. K., \& Begley, C. (2015). Risks associated with obesity in pregnancy, for the mother and baby: a systematic review of reviews. Obesity Reviews, 16 (8), 621-638.

Obesity and overweight, WHO, Erișim adresi: http://www.who.int/mediacentre/factsheets/fs311/en Erişim tarihi: 16.02.2018

Obesity And Pregnancy Clinical Practıce Guidelıne, Version 1.0 Guideline No. 2 Institute of Obstetricians and Gynaecologists, Royal College of Physicians of Ireland and Clinical Strategy and Programmes Directorate, Health Service Executive Date of publication - June 2011 Revision date - June 2013. Erişim adresi: https://www.hse.ie/eng/services/publications/clinical-strategy-andprogrammes/obesity-and-pregnancy-clinical-practice-guideline.pdf Erişim tarihi: 15.11.2018

O'Brien, T. E., Ray, J. G., \& Chan, W. S. (2003). Maternal body mass index and the risk of preeclampsia: a systematic overview. Epidemiology, 368-374.

Queensland Clinical Guideline: Obesity in pregnancy Queensland Clinical Guidelines Steering Committee Statewide Maternity and Neonatal Clinical Network (Queensland) December 2015 Erişim adresi: https://www.health.qld.gov.au/_data/assets/pdf file/0019/142309/g-obesity.pdf. Erişim tarihi: 15.10.2018

Powell, M. F., Morgan, C. J., Cantu, J. A., Sakawi, Y., Biggio, J. R., Tita, A. T., ... \& Edwards, R. K. (2017). Obesity and Neonatal Cord Blood Gas Results at Cesarean: Effect of Intraoperative Blood Pressure. American journal of perinatology, 34 (07), 716-721.

Rankin, J., Tennant, P. W., Stothard, K.J., Bythell, M., Summerbell, C. D., Bell, R. (2010). Maternal body mass index and congenital anomaly risk: a cohort study. Int J Obes (Lond)., 34(9):1371-80.

Sağlık Bakanlığ1 Riskli Gebelikler Yönetim Rehberi. Erişim adresi: https://sbu.saglik.gov.tr/Ekutuphane/kitaplar/risgebyonreh.pdf Erişim tarihi: 15.10.2018

Sharifzadeh, F., Kashanian, M., Jouhari, S., Sheikhansari, N. (2014). Relationship between prepregnancy maternal BMI with spontaneous preterm delivery and birth weight., L Obstet Gynaecol., 35(4):354-7. doi: 10.3109/01443615.2014.968101. 
Akın, B. (2020). Gebelik, doğum ve doğum sonu dönemde obezite - rehberler ve öneriler. Journal of Human Sciences, 17(1), 1-10. doi:10.14687/jhs.v17i1.5629

Sibai, B. M., Gordon, T., Thom, E., Caritis, S. N., Klebanoff, M., McNellis, D. (1995). Risk factors for preeclampsia in healthy nulliparous women: a prospective multicenter study. The National Institute of Child Health and Human Development Network of Maternal-Fetal Medicine Units. Am J Obstet Gynecol., 172(2 Pt 1):642-8.

Taşan, E. (2005). Obezitenin Tanımı, Değerlendirme Yöntemleri Obezitenin Tanımı, Değerlendirme Yöntemleri Ve Epidemiyolojisi, Turkiye Klinikleri J Int Med, 1(37):1-4.

Thrift, A. P., Callaway, L. K. (2014). The effect of obesity on pregnancy outcomes among Australian Indigenous and non-Indigenous women. Med J Aust., 201(10):592-5.

Tunçbilek, E.(2005). Obesite genetik bir hastalık midır? Cocuk Sağhğ ve Hastallkları Dergisi, 48: 101-108.

Türkiye Sağllk Araştırmas1, 2016, http://www.tuik.gov.tr/PreHaberBultenleri.do?id=24573

Ural, D., Kılıçkap, M., Göksülük, H., Karaaslan, S. D. D., Kayıkçığlu, M., Özer, N., \& Arınsoy, T. (2018). Türkiye'de obezite sıklığ1 ve bel çevresi verileri: Kardiyovasküler risk faktörlerine yönelik epidemiyolojik çalışmaların sistematik derleme, meta-analiz ve meta-regresyonu. Turk Kardiyol Dern Ars, 46 (7), 577-590.

Väänänen, A. J., Kainu, J. P., Eriksson, H., Lång, M., Tekay, A., \& Sarvela, J. (2017). Does obesity complicate regional anesthesia and result in longer decision to delivery time for emergency cesarean section?. Acta Anaesthesiologica Scandinavica, 61 (6), 609-618.

Velipaşaoğlu, M., \& Tanır, H. M. (2018). Obezite ve Doğum. Turkiye Klinikleri Journal of Gynecology ObstetricsSpecial Topics, 11 (1), 44-50.

Weight Gain During PregnancyReexamining the Guidelines. Editors: Kathleen M Rasmussen and Ann L Yaktine. Institute of Medicine (US) and National Research Council (US) Committee to Reexamine IOM Pregnancy Weight Guidelines. Washington (DC): National Academies Press (US); 2009.

\section{Extended English Summary}

The prevalence of obesity is increasing rapidly in the world and in our country. According to World Health Organization (WHO) data, in 2016, 39\% of adults aged 18 and over were overweight and 13\% were obese (WHO, 2016). The increasing prevalence of obesity in the community causes the presence of many health problems including diabetes, heart disease and certain cancers, as well as the likelihood of complications occurring in women at the same time during pregnancy, delivery and postpartum period. The most common of these complications include gestational diabetes mellitus (GDM), hypertensive disorders, cesarean delivery, neural tube defect for fetus, congenital anomaly, prematurity, admission to intensive care unit, stillbirth, macrosomia and childhood and adolescent obesity after delivery. Therefore, these pregnant women should be able to adjust their weight in the pre-pregnancy period, to control the strict weight gain from the early stages of pregnancy, to take precautions against possible complications before delivery and to be followed by an experienced team during the intrapartum period. The incidence of prenatal and peripartum mortality among obese mothers is 50\% higher than non-obese mothers. In addition to maternal mortality, maternal obesity has been reported to be associated with other comorbid conditions. The most common of these complications include gestational diabetes mellitus (GDM), hypertensive disorders and cesarean delivery. Maternal obesity, in addition to the mother, it increases the risk of neural tube defects, congenital anomaly, prematurity, macrosomia, admission to intensive care unit, stillbirth and obesity in childhood and adolescence for the fetus. Postpartum venous thromboembolism and wound infections are more common in obese pregnancies. In a study, it was determined that relative hypotension after spinal anesthesia during cesarean section was more prominent in women with BMI over $40 \mathrm{~kg} / \mathrm{m}^{2}$, and this situation negatively affected neonatal blood gas results. Avc1 (2015) also found that cesarean delivery, premature birth, shoulder dystocia and postpartum infection rates were significantly higher in obese pregnant women than non-obese pregnant women. In terms of anesthesia complications are more likely to occur. Excessive adipose tissue can make the use of epidural and spinal anesthesia difficult. 
Akın, B. (2020). Gebelik, doğum ve doğum sonu dönemde obezite - rehberler ve öneriler. Journal of Human Sciences, 17(1), 1-10. doi:10.14687/jhs.v17i1.5629

Obese pregnants should be given a different care than the normal weight pregnant women in order to prevent the complications that may occur during delivery and postpartum period. In many countries, there are maintenance guidelines created by using evidence-based studies for the follow-up and care of these pregnant women (IOM 2009; CMACE/RCOG Joint Guideline : Management of Women with Obesity in Pregnancy, 2013; Management of Women with Obesity in Pregnancy 2010; ACOG, Weight gain during pregnancy 2013; Queensland Clinical Guideline: Obesity in pregnancy 2015; Obesity And Pregnancy Clinical Practice Guideline, Royal College of Physicians of Ireland, 2011).

Generally in these guidelines:

*If possible, obese women lose weight in a controlled manner before they become pregnant.

$*$ Regulation of nutrition and encouraging to physical activity of overweight and obese pregnant women

* Since the risk of neural tube defect in the fetus will increase, they should take $5 \mathrm{mg}$ folic acid daily and continue during the first trimester of pregnancy.

*Blood sugar and blood pressure follow-up are more frequent in obese pregnants because of the increased risk of gestational diabetes and preeclampsia.

*Oral Glukose Tolerance Test (OGTT) should be applied to pregnants with Body Mass Index (BMI) $30 \mathrm{~kg} / \mathrm{m}^{2}$ and above at 14 th and 28th week of pregnancy, and reevaluation of pregnants with higher OGTT during pregnancy in terms of Type $2 \mathrm{DM}$ in postpartum period

*External monitoring of fetal heart rate during travay/labor will be difficult compared to monitoring internally

*Although thromboprophylaxis is not routinely recommended in obese pregnants, thromboprophylaxis in patients with BMI $40 \mathrm{~kg} / \mathrm{m}^{2}$ and above regardless of the type of delivery is recommended.

*Evaluation of pregnants who will have cesarean by obstetric anesthesia specialists in prenatal period, and initiation of antibiotics as prophylactic against the risk of infection in the postnatal period,

*It is recommended to have appropriate equipment (such as wide beds and stretchers, wide blood pressure cuffs and long needles), facilities and experienced personnel/staff for antenatal and intrapartum care.

* Obese women should continue to receive nutritional and exercise advice following delivery from an appropriately trained professional, with a view to minimising postpartum weight retention and encouraging weight reduction.

Pregnancy and obesity are discussed in the Risky Pregnancy Management Guidelines published by the Ministry of Health in Turkey (Ministry of Health in Turkey, Risky Pregnancy Management Guidelines, 2014). Thromboprophylaxis was recommended for all puerperants with BMI $>40 \mathrm{~kg} / \mathrm{m}^{2}$ However, there is no specific care guide for pregnancy and obesity. Taking preventive measures for complications that may occur during pregnancy, delivery and postpartum period; In the event of complications, timely intervention with adequate equipment and personnel is very important for maintaining maternal and infant health. Within the scope of efforts to prevent maternal and infant mortality in our country; there is a need to develop evidence-based care guidelines based on the current literature on obesity during pregnancy, delivery and postpartum period. 